\section{O ensino de} Sociologia à Iuz da temática indígena: a percepção de professores(as) acerca dos povos originários

Guilherme Luiz Pereira Costa ${ }^{1}$

\section{Karlla Christine Araújo} Souza ${ }^{2}$

\section{Guilherme Paiva de} Carvalho ${ }^{3}$

\footnotetext{
${ }^{1}$ Mestre em Ciências Sociais e Humanas pela Universidade do Estado do Rio Grande do Norte (PPGCISH/UERN).

Bolsista da Coordenação de Aperfeiçoamento de Pessoal de Nível Superior - CAPES.

E-mail: guilhermelpcosta15@gmail.com
${ }^{2}$ Doutora em Sociologia pela Universidade Federal da Paraíba (PPGS/UFPB).
Professora do PPGCISH/UERN
E-mail: karllasouza@uern.br

${ }^{3}$ Doutor em Sociologia pela Universidade de Brasília; Docente do PPGCISH/UERN e do POSENSINO/UERN/UFERSA/IFRN. E-mail: guimepaivacarvalho@gmail.com
}

\section{Sociology teaching in the light of indigenous theme: the perception of teachers about origining people}


O ensino de Sociologia à luz da temática indígena: a percepção de professores(as) acerca dos povos originários

\title{
Resumo
}

A Lei 11.645/2008 consiste em um importante mecanismo a favor de temas específicos na escola, visando ofertar uma educação capaz de reconhecer as diferenças e educar para seu respeito e valorização. Neste trabalho, ouvimos os(as) professores(as) formados(as) em Ciências Sociais acerca de suas percepções sobre os povos indígenas e como ocorre a gestão deste tema em suas escolas e salas de aula. Entrevistamos professores(as) de Sociologia no Ensino Médio, sendo todos(as) os(as) egressos da Universidade do Estado do Rio Grande do Norte (UERN) entre os anos de 2013 a 2017. Assim, a partir das falas dos(as) docentes, concluímos que não é possível uma mediação satisfatória da temática indígena sem uma formação que possibilite que o(a) docente conheça a História e Cultura Indígena.

Palavras-chave: Temática indígena; Ensino de Sociologia; Rio Grande do Norte.

\begin{abstract}
Law 11.645 / 2008 is an important mechanism in favor of specific themes in the school, aiming to offer an education capable of recognizing differences and educating for their respect and appreciation. In this work, we listen to teachers trained in Social Sciences about their perceptions about indigenous peoples and how this theme is managed in their schools and classrooms. We interviewed teachers of Sociology in high school, all of whom were graduates from the Universidade do Estado do Rio Grande do Norte (UERN) between the years 2013 to 2017. Thus, based on the speeches of teachers, we conclude that a satisfactory mediation of the indigenous theme is not possible without a training that allows the teacher to know the history and indigenous culture.
\end{abstract}

Keywords: Indigenous theme; Sociology teaching; Rio Grande do Norte. 


\section{Introdução}

Consideramos a Lei 11.645 de 2008 como um importante mecanismo a favor da discussão de temática indígena, historicamente excluída e/ou silenciada em currículo escolar. A respectiva lei surge visando a oferta de uma educação brasileira capaz de ensinar o respeito e valorização das diferenças em sociedade e entre os sujeitos que nelas estão inseridos.

Quando a Lei 11.645 de 2008 torna obrigatório o ensino da História e Cultura Africana, Afro-Brasileira e Indígena em instituições de ensino, se apresenta como marco legal e oferece diretrizes a respeito da mediação satisfatória de tais temáticas em sala de aula.

Neste trabalho, buscamos ouvir os(as) professores(as) formados(as) em Ciências Sociais acerca de suas percepções sobre os povos indígenas e como ocorre a gestão deste tema em suas escolas e salas de aula, considerando que não pode existir uma mediação da temática indígena em sala de aula sem que haja uma formação inicial que possibilite que o(a) docente conheça a História e Cultura Indígena.

Para isso, entrevistamos professores(as) de Sociologia no Ensino Médio que estão atuando em sala de aula enquanto docentes do respectivo componente curricular ou que já lecionaram-no em sua carreira, seja em instituições da rede pública (chamaremos os(as) docentes de Tainá, Gersem, Luiz, Peri e Inami) ou da rede privada de ensino (Serena, Mário). Além disso, todos(as) os(as) profissionais entrevistados(as) se formaram entre os anos de 2013 e 2017 no Curso de Licenciatura em Ciências Sociais da Universidade do Estado do Rio Grande do Norte (UERN) ${ }^{4}$.

Dito isso, vale considerar que "a entrevista é, portanto, uma forma de interação social. Mais especificadamente, é uma forma de diálogo assimétrico, em que uma das partes busca coletar dados e a outra se apresenta como fonte de informação" (GIL, 2008, p. 109), nos ajudando a ouvir os(as) professores(as).

Ao longo do texto, discutiremos a obrigatoriedade e inserção da temática indígena, bem como a temática Africana e Afro-Brasileira na escola a partir do que

\footnotetext{
${ }^{4}$ Delimitação estabelecida em nossa pesquisa de mestrado, cuja intenção era discutir a temática indígena a partir do Curso de Licenciatura em Ciências Sociais da UERN, levando em conta a atuação de professores(as) formados(as) dentro da vigência do projeto pedagógico do respectivo curso.
} 
O ensino de Sociologia à luz da temática indígena: a percepção de professores(as) acerca dos povos originários

dispõe a Lei 11.645 de 2008, refletindo acerca de uma educação multicultural com enfoque para a interculturalidade, conforme Candau $(2008 ; 2011)$ defende a fim de tornar o processo ensino-aprendizagem menos opressor e mais plural.

Em seguida, a partir das entrevistas realizadas com docentes da Educação Básica, trazemos as falas dos(as) professores(as) a respeito das populações indígenas no Brasil. Suas falas aparecem aqui quando eles(as) tratam das contribuições ou heranças dos povos originários para a sociedade que (re)conhecemos como Brasil.

Por último, ainda tendo em vista a percepção dos(as) docentes do componente curricular de Sociologia do Ensino Médio acerca dos povos originários, discutimos como as populações indígenas são vistas no tempo presente por nossos(as) interlocutores(as), considerando que conhecer a História e Cultura Indígena é entender que estes não são sujeitos que ficaram no passado da humanidade. Os indígenas fazem-se presentes!

Com isso, este artigo anela contribuir para o debate acerca do ensino de Sociologia no Ensino Médio, enquanto componente que abarca as demais Ciências Sociais e deve se preocupar em questionar o estabelecido, cumprindo seu papel de elaboração de um pensamento crítico. Logo, o ensino de Sociologia satisfatório deve proporcionar ao aluno o "estranhamento" necessário para perceber que, nos casos das populações indígenas, por exemplo, as diferenças são construídas a partir das relações sociais. O artigo debate, ainda, acerca da formação inicial na licenciatura em Ciências Sociais e contribui para fomentar a implementaridade da lei e das práticas que reconheçam a diversidade sociocultural em ambiente escolar.

\section{Abordagem multicultural: a temática indígena no contexto sócio-cultural brasileiro}

De acordo com Candau (2008), a oferta de uma educação multicultural favorece grupos sociais que estão historicamente silenciados, marginalizados ou excluídos dos espaços de sociabilidades e de tomada de decisões. Portanto, a abordagem multicultural consiste em oferecer a elaboração de um significativo mecanismo contra a opressão das minorias sociais, comprometida com políticas 
que possam ocasionar a inclusão e reconhecimento de diferentes visões de mundo, possibilitando um ambiente com equidade de oportunidade.

Assim, quando falamos de uma educação multicultural, estamos nos referindo àquela que envolve a almejada interação entre grupos distintos no processo educativo. Entretanto, essa interação não pode ser entendida como um produto pronto, como resultado final ou como solução para as situações de exclusão.

Entendemos que, na sociedade brasileira, buscar reverter o histórico de discriminação ou exclusão de sujeitos devido as suas diferenças não representa uma tarefa fácil. Em se tratando das inter-relações escolares, ainda em consonância com Candau (2008), o que se pode pensar para discutir as relações dentro desse ambiente de ensino-aprendizagem é um projeto pedagógico multicultural, cuja autora chama de educação intercultural.

Por sua vez, refletir acerca de uma educação intercultural consiste em considerar a interação entre esses grupos (oprimidos e privilegiados) dentro do perímetro da escola, reinventando a respectiva instituição de ensino para que assim possa, de fato, ocorrer a interculturalidade, acreditando que, independente do contexto em que esteja situada, a educação é pensada culturalmente para atender grupos específicos.

Candau (2011) salienta que as diferenças em âmbito escolar devem ser trabalhadas à luz do multiculturalismo interativo ou também conhecido como interculturalidade, sendo essa uma perspectiva que representa a interação entre as diferenças do ambiente de aprendizagem, fugindo da homogeneização.

A interculturalidade significa, portanto, a promoção do encontro de diferentes sujeitos de forma positiva. Além disso, uma perspectiva intercultural considera as diversas formas de conhecimentos e saberes, buscando ser portavoz de um diálogo. Destarte, deve-se ter uma "postura de valorização positiva das diferenças e combate às discriminações em toda a dinâmica escolar, o que exige um trabalho coletivo dos educadores, assim como espaços de formação continuada que abordem estas questões" (CANDAU, 2011, p. 252). Dessa maneira, uma escola vista pela lente intercultural tem um papel importante no desenvolvimento do respeito e da tolerância.

Por outro lado, é preciso reconhecer que o multiculturalismo possui outras faces, não é ele apenas interativo. Assim sendo, existe uma abordagem 
O ensino de Sociologia à luz da temática indígena: a percepção de professores(as) acerca dos povos originários

assimilacionista, afirmando que a sociedade é multicultural e acredita em um favorecimento da incorporação das diferenças de maneira homogênea, reproduzindo uma lógica presente nas escolas brasileiras: as diferenças são aceitas, mas são constantemente buscados mecanismos de incorporação, de assimilação do diferente a uma cultura hegemônica (CANDAU, 2011).

Outra abordagem do multiculturalismo é conhecida como diferencialista ou monocultural plural. Aqui enfatiza-se o repúdio à assimilação, uma vez que ela silencia, nega as diferenças. Então, acredita-se na promoção das diferenças e expressão das identidades culturais. Entretanto, essa ênfase demasiada pelo reconhecimento das diferenças, torna essa vertente em posição essencialista, causando a segregação ou divisão das identidades sociais, impedindo o encontro positivo proposto ela interculturalidade.

No sentido intercultural, considerando a legislação e os fundamentos políticos educacionais que norteiam as relações traçadas em ambiente escolar, os movimentos sociais têm contribuído para pressionar o Estado a empreender estratégias para assegurar a inclusão de temáticas específicas que oferecem a possibilidade de compreender de forma positiva a presença das diferenças no Brasil.

Por via da Lei 10.639 de 2003, modificando a Lei de Diretrizes e Bases da Educação Nacional (LDB) de 1996, fica instituído que instituições de ensino devem inserir a História e Cultura Africana e Afro-Brasileira como temática nos currículos escolares, procurando superar o quadro de inferiorização, preconceito e discriminação, sobretudo por causa da cor da pele.

Contudo, considerando toda a sociodiversidade encontrada em território brasileiro e o histórico de exterminação dos povos, fica o entendimento de que a Lei 10.639 de 2003 não abarcava todos as diferenças. Assim sendo, em 2008, modificando a LDB mais uma vez, os povos indígenas são inseridos na discussão:

Essa Lei incorporou a Lei 10.639/2003 ou é outra lei? Ou seja, são duas leis diferentes? Se forem duas leis, porque o texto da Lei $n^{\circ}$ 11.645/2008 afirma "História e Cultura Afro-Brasileira e Indígena"? Lembrando que as leis ou a Lei no preâmbulo de seu/s texto/s estar escrito que se alterou a Lei $n^{\circ} 9.394$ de 20 de dezembro de 1996, a LDBEN, conhecida como LDB, que em seus artigos 26-A e 79-B previa a inclusão da temática étnico-racial no ensino. Em outras palavras, as leis $n^{\circ} 10.639 / 2003$ e $n^{\circ} 11.645 / 2008$ representam para os movimentos sociais, para as organizações 
negras e indígenas, bandeiras de mobilizações históricas, todavia, juridicamente a LDBEN é a legislação que rege a Educação Brasileira (SILVA, 2017, p. 96).

A Lei 11.645 de 2008 não é uma nova lei sancionada para privilegiar apenas as populações indígenas. Dessa forma, quando a respectiva lei assegura que as instituições de ensino devem ofertar obrigatoriamente a História e a Cultura Africana, Afro-Brasileira e Indígena, ela está incluindo a temática indígena na discussão. Portanto, não é um mecanismo próprio para tratar dos povos originários, mas para debater de forma conjunta:

O desafio das escolas é garantir espaços nos currículos e nas salas de aula para a inclusão positiva da História e Cultura de negros e indígenas. É importante que, para uma adequada aplicabilidade dessas determinações legais, as instituições educacionais repensem seu papel na formação de indivíduos preparados para viver e conviver em ambientes de diversidade, reconhecendo-se como atores importantes dos processos históricos, independentemente de sua condição étnica, econômica ou social (FONTENELE; CAVALCANTE, 2020, p. 03).

Mesmo considerando que não existe necessariamente uma importância de certa temática em detrimento de outra, a nível de recorte de pesquisa, decidimos investigar como professores(as) de Sociologia do Ensino Médio percebem a História e a Cultura Indígena em território brasileiro, buscando discutir, sobretudo a mediação em sala de aula.

Para isso, torna-se interessante mencionar que a vergonha, fruto de um longo período de perseguição e discriminação, fez com que muitos povos indígenas, querendo esconder suas origens, se declarassem como caboclos. Essa dominação consistia em uma tentativa de se aproximar do dito "homem branco" e ser mais "civilizado", camuflando qualquer associação a categoria índio.

Por um lado, encontram-se os que afirmam seu orgulho de fazer parte dos povos originários; do outro, aqueles que ainda temem ser alvos de julgamentos quanto a sua capacidade cognitiva e/ou biológica. De acordo com Santos (2009), tal julgamento se firma nas ideias cientificamente ultrapassadas de evolução, jogando as populações indígenas na zona do não-ser.

Embora a produção científica acerca da temática indígena, especificamente no ensino de Sociologia, seja bastante limitada, o trabalho de 
O ensino de Sociologia à luz da temática indígena: a percepção de professores(as) acerca dos povos originários

uma professora do respectivo componente curricular na Educação Básica nos ajuda a problematizar como se dá, por exemplo, o contato e/ou interesse dos(as) docentes:

\begin{abstract}
Quando comecei a lecionar no IFBA, estava cursando mestrado em antropologia na UFBA - Universidade Federal da Bahia, tendo como tema educação escolar indígena. Com a conclusão do mestrado e focada na temática indígena, passei a ampliar a abordagem da discussão sobre etnia, que realizo com foco em etnias indígenas, e traçar relações com as questões indígenas em aulas diversas. Tal ampliação não se deu somente em relação à questão indígena, mas também em relação a alguns outros conteúdos, tais como cultura, etnocentrismo, identidade, raça e etnia. [...] Transformar tais conteúdos em unidade temática trouxe a possibilidade de aprofundar com os estudantes, por exemplo, como 0 racismo se estruturou historicamente no Brasil, desconstruir uma série de estigmas em relação à indianidade e também a necessária desconstrução da concepção de cultura essencialista, e assim também das culturas escolar e acadêmica conservadoras (CHATES, 2015, 126).
\end{abstract}

Diante da experiência compartilhada por tal pesquisadora e docente do componente curricular de Sociologia, se torna imprescindível levar em conta seu interesse pessoal, bem como sua trajetória acadêmica antes de atuar diretamente em sala de aula. A professora supracitada frisa que a abordagem de certos temas está interligada com seus estudos prévios.

Levando em consideração a experiência compartilhada por Chates (2015), entendendo que se trata da primeira pesquisa acerca do ensino da temática indígena no Ensino de Sociologia disponível no site Periódicos Capes, buscamos escutar outros(as) professores(as) de Sociologia, haja vista que este é um componente curricular na Educação Básica preocupado com a visão de mundo, da percepção das diferenças dos(as) estudantes (BRIDI; ARAÚJO; MOTIM, 2009).

No mais, optamos por ouvir especificamente aqueles(as) professores(as) formados(as) pela UERN, tendo em vista que eles(as) podem nos apresentar um panorama do(a) egresso(a) do Curso de Licenciatura em Ciências Sociais frente à temática indígena. 


\section{Considerações sobre os povos indígenas e a cultura brasileira}

Os nomes utilizados nesse texto são todos fictícios, portanto, sendo homenagem a nomes de indígenas da vida real, sujeitos que lutam por uma sociedade mais justa, buscando a valorização e o reconhecimento dos povos indígenas brasileiros. Além disso, também utilizamos nomes de indígenas da literatura brasileira, do cinema, de telenovelas ou desenhos animados.

Os professores Gersem ${ }^{5}$, Mário ${ }^{6}$, assim como as professoras Tainá7 e Serena ${ }^{8}$, concluíram a pós-graduação. Com exceção apenas de Serena, que tem o título de especialista em Integração Racial na escola, os demais são mestres em ensino ou em Ciências Sociais e Humanas. Além disso, Gersem, durante a nossa pesquisa, está cursando Doutorado em Ciências Sociais.

Por sua vez, os professores Luiz $^{9}$, Peri ${ }^{10}$ e Inami ${ }^{11}$ afirmam não terem dado continuidade a uma formação institucionalizada, sendo o Curso de Licenciatura em Ciências Sociais da UERN sua única formação.

Dessa maneira, questionamos se os(as) professores(as) inseridos na nossa pesquisa percebem [se houve] a contribuição das populações indígenas na formação do Brasil e, se a resposta fosse sim, qual teria sido a contribuição deixada para a contemporaneidade.

Sem exceção, todos(as) eles(as) os(as) professores(as) entrevistados(as) apontam elementos os quais acreditam ser contribuições advindas das populações originárias do Brasil que se tornaram parte dos elementos constitutivos da sociedade que se formou aqui.

\footnotetext{
${ }^{5}$ Concluindo a graduação em 2016, estando com 28 anos de idade no momento da entrevista, o referido professor atua na rede pública de ensino do estado do Rio Grande do Norte desde 2008, lecionando nas cidades de Portalegre e Francisco Dantas.

${ }^{6}$ Formado em 2013, atua na rede privada de ensino, na cidade Mossoró, estando com 36 anos de idade.

7 Aos 43 anos de idade, atua na rede pública de ensino, lecionando na cidade de Mossoró. Formada em 2017.

${ }^{8}$ Concluindo a graduação em 2014, a professora de 46 anos de idade que atua na rede privada nos informou que, no ano de 2020, não está lecionando o componente curricular de Sociologia, mas que já lecionou nos anos anteriores na cidade de Caraúbas, no Rio Grande do Norte.

${ }^{9}$ Graduado em 2013, o referido professores atua na rede pública de ensino, em Almino Afonso-RN, estando com 33 anos de idade.

${ }^{10}$ Lecionando Sociologia na rede pública, na cidade de Grossos-RN, aos 27 anos, o professor Peri nos informa que conseguiu seu diploma em 2016.

${ }^{11}$ Formado em 2017, agora aos 30 anos de idade, leciona o componente curricular de Sociologia na rede privada, na cidade de Mossoró.
} 
O ensino de Sociologia à luz da temática indígena: a percepção de professores(as) acerca dos povos originários

Assim, entre eles(as), Gersem cita que "os povos indígenas não apenas preservaram e preservam as terras, eles nos mostram cotidianamente uma relação íntegra com a natureza, com a religiosidade e a cultura" (Gersem). Adicionam ainda que "muitas de nossa culinária, vestimentas, músicas, miscigenação, cultivo da terra, língua, são formas que ganharam representatividade em nossa sociedade" (Inami).

Entendemos que aqueles(as) professores(as) que recebem uma formação inicial e/ou continuada que teve como base a diversidade cultural e política, podem representar, na escola situada na sociedade envolvente, a construção de uma nova percepção a respeito dos povos indígenas, favorecendo discussões que levam ao respeito de valorização das diferenças que permeiam o Brasil.

Nesse sentido, conforme afirma Russo e Paladino (2016, p. 918), "[...] consideramos de suma relevância para o avanço na efetivação da lei priorizar a formação inicial e continuada de professores ${ }^{12}$, acreditando que eles são os agentes facilitadores fundamentais da formação crítica e cidadã das futuras gerações". Portanto, apenas a Lei 11.645 de 2008, sem outras estratégias para especializar os sujeitos inseridos nesse processo, não representa efetividade do ensino das temáticas exigidas.

Continuando com o que pensam sobre as contribuições advindas das populações indígenas para a dita sociedade brasileira, os(as) demais professores(as) pensam de forma semelhante. Eles(as) mencionam os seguintes aspectos das culturas indígenas:

Vários meios podem alertar sobre isso. Uma das causas que muitos povos indígenas defendem é a defesa as suas terras, onde possam preservá-las e isso nos ensina o quão é importante para a vida humana. Nos ensinaram muitos aprendizados de cura e até hoje permanecer em nosso meio como os chás, alimentos, objetos, dentre outros (Mário).

Ah, meu querido, tantas! A gente pode elencar as nossas tradições, os nossos costumes. A gente deve muito a eles. Conhecimentos sobre os céus, a questão da agricultura, no quesito medicamentos, plantas, conhecer a região, o Brasil, as terras onde se podia plantar, onde tinha água. Quer dizer, a contribuição desses povos até hoje eu considero de forma

12 Compreendemos formação continuada como processo permanente e constante de aperfeiçoamento dos saberes necessários à atividade dos educadores. Muitas ações podem compor as estratégias para tal renovação. Contudo, é obrigação do estado garantir políticas públicas, programas e cursos que visem a formação continuada de docentes. 
significativa e eu passo isso para os alunos na medida que a gente pode e tem acesso quando vai falar. A gente tem uma dívida muito grande com esses povos, eu digo a eles. A gente tem uma dívida que não vai pagar. Então, é uma contribuição enorme para a cultura brasileira, pro nosso povo (Luiz).

Nós somos o povo mais lindo. Temos uma identidade composta da contribuição de outros povos. Deles, temos a cultura do milho e da batata doce, por exemplo. Foi com eles que os 'invasores' aprenderam a conhecer as nossas terras. Lembro que eles tinham seus rituais pra agricultura (Serena).

Eles/as foram os primeiros habitantes dessa terra. Antes da invasão dos portugueses, o Brasil era povoado por uma enorme diversidade de populações indígenas. E eles contribuíram de diversas formas para o desenvolvimento desse país: agricultura, meio ambiente, pesca, culinária, ritos, crenças e religião, os costumes e sua vasta cultura. A luta dos povos indígenas não visa apenas o reconhecimento de sua cultura (ritos e credos). Eles reivindicam suas terras que são extirpadas pelo homem branco única e exclusivamente por interesses econômicos e pela sua ganância (Tainá).

É possível perceber que diversos aspectos culturais são citados pelos(as) professores, indo desde a religião à relação com o meio ambiente. Além disso, as técnicas utilizadas pelos povos originários, sobretudo na agricultura, aparecem nas falas dos(as) professores(as), reconhecendo que, conforme explica Ribeiro (2009, p. 105), "do indígena aproveitou a colonização europeia a técnica de coivara (clarear os campos a fogo), que até hoje não foi substituída por processos mais modernos, constituindo-se numa prática sumariamente nociva à economia agrícola".

Além disso, podemos acrescentar também que,

[...] desconhecendo embora o uso de instrumentos de ferro, as técnicas agrícolas indígenas eram bastante eficientes $\mathrm{e}$ perfeitamente ajustadas às condições de seu meio ambiente. Baseavam-se, como ainda hoje, num saber milenar - o conhecimento objetivo da natureza e suas leis - advindo da observação e da experimentação (RIBEIRO, 2009, p. 105).

Ainda que esbocem conhecimentos mais genéricos a respeito de aspectos culturais herdados das populações indígenas ao longo da história do nosso país, é possível perceber que existe uma concepção positiva de tal herança. Ou seja, os(as) professores(as) de Sociologia entrevistados(as) acreditam que os 
O ensino de Sociologia à luz da temática indígena: a percepção de professores(as) acerca dos povos originários

"primeiros habitantes dessa terra" deixam contribuições que não foram desfeitas, mas que perpassam o processo de colonização.

Porém, a omissão desta temática nos currículos deflagra a urgência de novas configurações de currículo, e mais especificamente, o currículo para o ensino de Ciências Sociais. Para o currículo das licenciaturas em geral, destacase a necessidade da criação de novos componentes curriculares específicos na universidade. Para o currículo das Ciências Sociais no ensino superior e na educação básica, é indispensável buscar estratégias para abarcar a História e Cultura Indígena, a fim de que esta temática não fique a cargo do empenho individual de cada docente em suas respectivas atuações escolares.

\section{Existência e resistência: os povos indígenas no tempo presente}

Em consonância com Almeida (2010) e Cunha (2012), a partir das falas dos(as) interlocutores(as), existe o entendimento de que os povos indígenas fazem parte do nosso presente, contrariando a ideia de assimilação que alguns acreditavam ser iminente. Não sendo os povos originários, portanto, uma lenda do folclore brasileiro.

Dessa forma, além de reconhecer as contribuições fundantes das populações indígenas no desenvolvimento de prática para a agricultura ou para a dieta, há quem se queixe do tratamento oferecido a essas populações, denunciando a falta de respeito e ciência acerca de suas especificidades:

Lutam pelos direitos básicos como qualquer cidadão: educação, saúde, saneamento e por proteção aos seus territórios. A Constituição Federal assegura alguns direitos aos indígenas, no entanto, na prática, o que vemos são os indígenas sendo privados e massacrados por esse (des)governo que não tem o mínimo de respeito e sensibilidade em relação a esses povos que foram (e são) muito importantes para a constituição do povo brasileiro. Os indígenas estão sofrendo sobremaneira nessa pandemia, com várias vítimas fatais em todas as etnias espalhadas em nosso país. Não há uma política pública para a proteção desses povos e se continuar assim, eu temo pelo pior. O Brasil precisa valorizar e reconhecer a importância dos povos indígenas que ajudaram a escrever e a construir a história do Brasil (Tainá).

Exatamente como esclarece a professora, desde a promulgação da Constituição de 1988, os direitos dos indígenas diante do Estado foram Mosaico - Volume 12 - No 19 - Ano 2020 
reconhecidos, fazendo com que esses povos, em território brasileiro, deixassem de ser tratados como dependentes e se tornassem autônomos, pelo menos na letra da lei. Tornar-se-iam protagonistas porque essa conquista histórica não foi fruto de paternalismo do Estado.

Na época (1970-1980), o empenho de lideranças indígenas, com apoio de pesquisadores(as) e organizações sociais, tomou forma como importante período de resistência, atuação política e interesses coletivos, conforme assevera Bicalho (2010) em relação ao Movimento Indígena Brasileiro.

Nesse período, pela primeira vez, os indígenas tiveram assegurado mais do que o direito de existir. Após a promulgação da Constituição Federal de 1988, as populações indígenas conseguem o direito de "ser indígena", resultado de suas lutas:

É sobretudo com base nos direitos constitucionais previstos no art. 231, assumidos enquanto uma importante conquista de suas lutas antes e junto à Constituinte de 1987-1988, que os movimentos indígenas no Brasil têm desenvolvido os seus processos de resistência territorial e de busca de uma maior autonomia na interlocução com o Estado, numa espécie de 'alforria' ou 'emancipação' - constitucionalmente respaldada -, em relação ao controle tutelar exercido pelo SPI e pela Funai. Para os povos indígenas a força simbólica daqueles reconhecimentos foi tão intensa que meses após a promulgação da Constituição de 1988 o país observou a ocorrência de um 'boom' de organizações e articulações indígenas de caráter étnico, inter-étnico, local, regional, 'nacional' e até mesmo transfronteiriço (LACERDA, 2014, p. 377).

A Constituição Federal de 1988 é considerada como a passagem da ideia de necessidade de integração para o reconhecimento da diferença e de direitos dos povos indígenas, levando em conta que, anteriormente, toda a legislação entendia ser dever do Estado resguardar o respeito dos direitos de igualdade dos povos indígenas (ALMEIDA, 2010).

No entanto, por essa igualdade se entendia como sinônimo de homogeneidade, de incorporação. Ou seja, todos os grupos marginalizados, como os povos indígenas, deveriam ser assimilados culturalmente na sociedade nacional. Logo, com isso, a integração não possibilitaria uma compreensão das diferenças, causando discriminação, vergonha e ocultamento de identidades.

Segundo Bicalho (2010) e Munduruku (2012), com as mobilizações, a partir da década de 1970, têm tomado rumos favoráveis aos indígenas, embora se 
O ensino de Sociologia à luz da temática indígena: a percepção de professores(as) acerca dos povos originários

deva considerar todos os atos de resistência desde o período de colonização, para sermos mais justos. Entretanto, como trata Cunha (2012), não devemos esquecer que essa é uma luta que deve ser travada em parceria tanto com o Estado brasileiro quanto à comunidade internacional.

Tendo em vista o legado dos povos indígenas à sociedade que aqui se formou, o professor Peri salienta que "eles são os pioneiros do nosso território. Se não houvesse a invasão europeia, nós seriamos imersos na cultura indígena. Devemos a eles o respeito de conhecer a sua cultura e respeitá-la".

Levando em consideração a colocação feita pelo professor, há de se concordar que não podemos pagar uma dívida alimentada ao longo da história do Brasil. No entanto, podemos fazer o necessário para possibilitar uma reparação histórica, elaborando e oferecendo ferramentas para ultrapassar concepções coloniais de infantilidade e inferioridade atribuídas às populações indígenas.

Considerando o papel da escola à frente da temática aqui discutida, os(as) professores(as) ressaltam que as instituições as quais eles(as) estão vinculados(as), sejam elas públicas ou privadas, não interferem diretamente em suas práticas pedagógicas, dando a sensação de maior liberdade e autonomia para a prática docente. Assim, é possível entender que fica a cargo do(a) docente o comando de sua sala de aula.

Porém, a nosso ver, o fato de as escolas não interferirem no trabalho dos(as) professores(as) de Sociologia entrevistados(as), significa que elas também não incentivam o debate a respeito da História e cultura Indígena. Com base nas entrevistas, percebe-se que não existe um empenho das instituições no que diz respeito à elaboração de mecanismos para favorecer o debate da temática indígena dentro de seus perímetros.

Assim, Gersem salienta que, a respeito da escola onde leciona, "a postura é a mesma da maioria delas: trata a temática como folclore" (Peri). Além disso, quando resolve tratar de tal temática, "a escola fala no dia da consciência negra. Trabalho individualmente na sala nos outros dias" (Gersem).

Desse jeito, Gersem faz ressalva a seu interesse e empenho pessoal em mediar a temática indígena no Ensino Médio, para além do dia da consciência negra. O professor Inami também enfatiza que "a escola deixa a cargo do 
professor trabalhar esta ou outras temáticas", não existindo, portanto, momentos de debate específicos acerca das exigências da Lei 11.645 de 2008.

Continuando com os relatos sobre a postura das escolas diante da temática indígena, tratando sobre a existência ou não de algum auxílio para mediar a discussão nas referidas instituições em que lecionam, outros(as) professores(as) citam a falta de abordagem e incompreensão por parte da gestão escolar:

Pouco discutido. Acho que deveria estar mais a nossa frente. Nós não temos datas especiais em relação à escola. Assim, como decorrente a outros assuntos, a escola não tem datas, não faz parte do calendário, não é parte do calendário. Então, assim, não, a escola não proíbe, mas também não estimula essa temática. De maneira geral, apenas a gente, os professores, das áreas afins podem tratar. Podemos tratar a temática assim como a gente já faz. É um assunto muito relevante. Sempre que a gente tem a oportunidade, bate nessa tecla. É uma temática bacana, fantástica e que precisa ser estimulada nas nossas escolas (Luiz).

Eles não têm a compreensão que temos, sabe? Não tem um entendimento como nós temos, dessa contribuição e tal. Mas, não interfere nas nossas discussões. Até dá um suporte, inocente, mas dá. Trabalhamos a Hora Cívica. E, geralmente, quando eu coordeno, sempre se espera um tema assim. Não de forma robotizada, mas, crítica, reflexiva. Então, a postura da escola que trabalho, hoje, é de apoiar do seu jeito, nas suas limitações de conhecimento (Serena).

Visualizando mais uma vez o empenho individual de cada docente em suas respectivas escolas e o não comprometimento por parte das instituições onde eles(as) lecionam na elaboração de estratégias para buscar abarcar a História e Cultura Indígena no trabalho letivo, mais uma professora confirma as falas de alguns de seus colegas.

A respectiva professora ratifica que não existe um momento específico no calendário letivo da sua escola ou qualquer evento "que contemple a temática, mas acredito que professores de humanas, Sociologia, História, Geografia, Literatura e Filosofia explorem essa temática em sala de aula. Eu trabalho com esse assunto nas aulas de Sociologia" (Tainá).

Então, fica claro a importância dada ao trabalho de cada professor na tentativa de construir elementos para favorecer o debate acerca da temática indígena na escola. Ainda que essa última fala mencione o trabalho de professores das ciências humanas e a Lei 11.645 de 2008 reconheça a 
O ensino de Sociologia à luz da temática indígena: a percepção de professores(as) acerca dos povos originários

necessidade de um ensino transdisciplinar, constitui um debate à parte discutir como os(as) professores de diferentes disciplinas podem se articular de forma a ocasionar melhor desenvolvimento da temática indígena na prática escolar.

\section{Considerações finais}

A partir das falas dos(as) professores(as) de Sociologia no Ensino Médio formados(as) pelo Curso de Licenciatura em Ciências Sociais da UERN, é possível perceber que existe uma percepção construtiva da presença das populações indígenas em território brasileiro, sendo um indicativo para refletir a respeito da inserção da História e da Cultura Indígena no ensino básico.

Entretanto, não podemos considerar como suficientes as formas, até então, possíveis de encontrar aberturas para a temática indígena no referido curso de graduação. Assim, entendemos ser necessário buscar novos horizontes, uma vez que, o maior desafio do ensino de Sociologia tem sido garantir espaços nos currículos e nas salas de aula para a inclusão positiva deste componente curricular na escola, e consequentemente, da História e Cultura de negros e indígenas enquanto conteúdo seu.

Torna-se interessante considerar que, quando os(as) professores reconhecem as diferenças sociais entre os sujeitos como elemento significativo para tratar de forma positiva o estranhamento, fica mais fácil a efetividade da Lei 11.645 de 2008, haja vista que não é possível ensinar o que não sabemos. Ou seja, nossos(as) interlocutores(as) demonstram interesse em aprender mais acerca da História e Cultura Indígena.

Ainda que alguns(as) docentes usem conhecimentos bastante genéricos para tratar das contribuições dos povos indígenas no que diz respeito a formação da sociedade brasileira, citando os hábitos de higiene e alimentares ou mesmo as técnicas de agricultura, por exemplo, é interessante notar que existe a percepção de valorização de tal herança.

É possível concluir que todos(as) professores(as) entrevistados(as) reconhecem a contribuição das populações indígenas para a constituição da sociedade brasileira, bem como entendem ser necessário trabalhar a referida temática nas escolas e/ou na educação superior, no entanto, ainda podemos 
avistar um campo de disputa para decidir a qual componente curricular compete trabalhar a história e a cultura dos povos originários.

No mais, para além dessas contribuições, elementos herdados das populações indígenas que se mantêm até a contemporaneidade, podemos mencionar que também existe uma visão a respeito das populações indígenas no tempo presente. Ou seja, nossos(as) interlocutores (as) continuam considerando a presença de tais populações na atualidade, não citando os povos originários como sujeitos destinados ao passado do nosso país.

Artigo recebido em 22 de Outubro de 2020. Aprovado para publicação em 23 de Novembro de 2020.

\section{Referências}

ALMEIDA, Maria Regina Celestino de. Os índios na História do Brasil. Rio de Janeiro: Editora FGV, 2010.

BICALHO, Poliene Soares dos Santos. Protagonismo Indígena no Brasil: Movimento, Cidadania e Direitos (1970-2009). 2010. 468 f. Tese (Doutorado) Curso de Programa de Pós-graduação em História, Universidade de Brasília, Brasília, 2010.

BRIDI, Maria Aparecida; ARAÚJO, Sílvia Maria de; MOTIM, Benilde Lenzi. Ensinar e aprender Sociologia no Ensino Médio. São Paulo: Contexto, 2009.

CANDAU, Vera Maria. Multiculturalismo e educação: desafios para a prática pedagógica. In: MOREIRA, Antonio Flávio; CANDAU, Vera Maria. Multiculturalismo: diferenças culturais e práticas pedagógicas. Petrópolis: Editora Vozes, 2008. p. 13-37.

CANDAU, Vera Maria. "Diferenças Culturais, Cotidiano Escolar e Práticas Pedagógicas". Currículo Sem Fronteiras, v. 11, n. 2, p.240-255, 2011. Disponível em: http://www.curriculosemfronteiras.org/vol11iss2articles/candau.pdf. Acesso em outubro de 2020.

CHATES, Taíse de Jesus. "Ensino de Sociologia e Lei 11.645/08: experiências de ensino, pesquisa e extensão no IFBA". Revista em Debate, Florianópolis, n. 14, p. 122-139, $2015 . \quad$ Disponível em: https://periodicos.ufsc.br/index.php/emdebate/article/download/19803532.2015n14p122/32248. Acesso em outubro de 2020.

CUNHA, Manuela Carneiro da. Índios no Brasil: História, direitos e cidadania. 1. ed. São Paulo: Claro Enigma, 2012. 
O ensino de Sociologia à luz da temática indígena: a percepção de professores(as) acerca dos povos originários

FONTENELE, Zilfran Varela; CAVALCANTE, Maria da Paz. "Práticas docentes no ensino de História e Cultura Afro-Brasileira e Indígena". Educação e Pesquisa, São Paulo, v. 46, p. 01-20, 2020. Disponível em: https://www.revistas.usp.br/ep/article/view/166362/159102. Acesso em outubro de 2020.

LACERDA, Rosane Freire. "Volveré, y Seré Millones": Contribuições Descoloniais dos Movimentos Indígenas Latino Americanos para a Superação do Mito do Estado-Nação. 2014. 2 v. Tese (Doutorado) - Curso de Programa de Pósgraduação em Direito da Faculdade de Direito, Universidade de Brasília, Brasília, 2014.

MUNDURUKU, Daniel. O caráter educativo do Movimento Indígena Brasileiro (1970-1990). São Paulo, Paulinas, 2012.

RIBEIRO, Berta. O índio na história do Brasil. 12. ed. São Paulo: Global, 2009.

RUSSO, Kelly; PALADINO, Mariana. "A Lei n. 11.645 e a visão dos professores do rio de janeiro sobre a temática indígena na escola". Revista Brasileira de Educação, Rio de Janeiro, v. 21, n. 67, p.897-921, out. 2016. Disponível em: https://www.scielo.br/pdf/rbedu/v21n67/1413-2478-rbedu-21-67-0897.pdf. Acesso em outubro de 2020.

SANTOS, Boaventura de Souza. Para além do Pensamento Abissal: das linhas globais a uma ecologia de saberes. In: SANTOS, Boaventura de Sousa; MENESES, Maria Paula (org.). Epistemologias do Sul. Coimbra: Almeidina, 2009. p. 09-20.

SILVA, Edson. "Os Povos Indígenas e o Ensino: Reflexões e Questionamentos às Práticas Pedagógicas". Tópicos Educacionais, [S.I.], v. 23, n. 2, mar. 2017. Disponível em: https://periodicos.ufpe.br/revistas/topicoseducacionais/article/view/235106. Acesso em outubro de 2020. 